\title{
The roles of medical examiners in the COVID-19 era: a comparison between the United States and Italy
}

\author{
Matteo Moretti ${ }^{1}$ - Ashim Malhotra ${ }^{2}$ Silvia D. Visonà ${ }^{1} \cdot$ Sheree J. Finley $^{3} \cdot$ Antonio Marco Maria Osculati $^{1}$. \\ Gulnaz T. Javan ${ }^{4}$ (D)
}

Accepted: 7 January 2021 / Published online: 13 February 2021

(c) Springer Science+Business Media, LLC, part of Springer Nature 2021

\begin{abstract}
Italy and the United States are two of the countries most affected by SARS-CoV-2 (COVID-19), with more than 240,760 confirmed cases in Italy and 2,699,658 in the United States (as of July 2, 2020). The current COVID-19 pandemic has led to substantial changes in many fields of medicine, specifically in the forensic discipline. Medicolegal activities related to conducting autopsies have been largely affected by the COVID-19 pandemic. Postmortem examinations are generally discouraged by government regulations due to the risk of spreading the disease further through the handling and dissection of bodies from patients who succumbed to COVID-19 infection. There is a paucity of data regarding the persistence of SARS-CoV-2 in bodies, as well as concerning the reliability of swabbing methods in human remains. On the other hand, the autopsy is an essential tool to provide necessary information about the pathophysiology of the disease that presents useful clinical and epidemiological insights. On this basis, we aim to address issues concerning general medical examiner/coroner organization, comparing the Italian and American systems. We also discuss the pivotal roles of forensic pathologists in informing infectious disease surveillance. Finally, we focus on the impact of COVID-19 emergency on medicolegal practices in Italy and the United States, as well as the responses of the forensic scientific community to the emerging concerns related to the pandemic. We believe that stronger efforts by authorities are necessary to facilitate completing postmortem examinations, as data derived from such assessments are expected to be paramount to improving patient management and disease prevention.
\end{abstract}

Keywords COVID-19 $\cdot$ Medical examiner $\cdot$ Autopsy $\cdot$ United States $\cdot$ Italy

Matteo Moretti and Ashim Malhotra contributed equally to this work.

Gulnaz T. Javan

gjavan@alasu.edu

1 Department of Public Health, Experimental and Forensic Medicine, University of Pavia, via Forlanini, 12, 27100 Pavia, Italy

2 College of Pharmacy, California Northstate University, Elk Grove, CA, USA

3 Department of Physical Sciences, Alabama State University, Montgomery, AL, USA

4 Forensic Science Program, Department of Physical Sciences, Alabama State University, AL, Montgomery, USA

\section{Introduction}

The novel coronavirus (severe acute respiratory syndrome coronavirus-2, SARS-CoV-2) is a highly contagious virus that was first reported in Wuhan, China, in December 2019, and then spread rapidly to many countries all over the world. Most infected people have an asymptomatic or a mild atypical respiratory disease (so called coronavirus disease or COVID19), but about $20 \%$ develop a more severe clinical diagnosis with a high mortality rate. Italy and the United States are among the countries with the highest number of COVID19 cases globally Fig. 1 [1]. At present (July 2, 2020), the number of COVID-19 cases is 240,760 in Italy and 2,699,658 in the United States. According to the Center for Systems Science and Engineering (CSSE) at John Hopkins University, the number of deaths that are believed to have been caused by SARS-CoV-2 are 34,818 in Italy and 128,677 in the United States [2,3]. As we explain later, governments collect their 


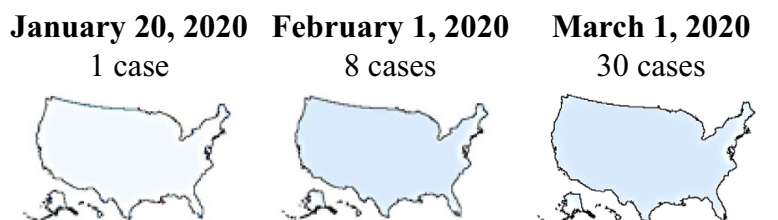

January 20, 2020 February 1, 2020 1 case

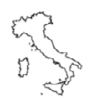

2 cases

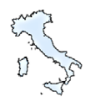

March 1, 2020

1,694 cases

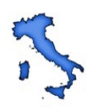

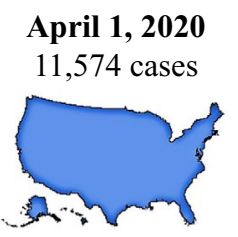

April 1, 2020

110,559 cases

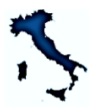

May 1, 2020

$1,103,000$ cases

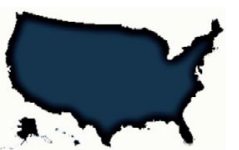

May 1, 2020

207,428 cases

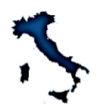

June 1, 2020

$1,746,019$ cases

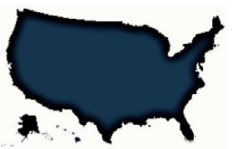

June 1, 2020

232,248 cases

0

cases

$1,000,000$

cases

Fig. 1 Comparison of severe acute respiratory syndrome coronavirus 2 (SARS-CoV-2 or COVID-19) cases reported for the United States (top panel) and Italy (lower panel). The first reported U.S. case occurred on January 22, 2020 and is shown along with the case numbers for both countries for 1 February 2020, 1 March 2020, 1 April

statistics differently, making any cross-border comparison, be it infections, recoveries, or deaths, imprecise.

The COVID-19 pandemic has caused crucial adjustments in many fields of medicine, specifically in the medicolegal field. SARS-CoV-2 is categorized as a hazard group 3 (HG3) coronavirus. This pathogen requires four areas of attention: i) risk assessment, ii) pathological determinations, iii) universal standard preventative measures, and iv) standard operating procedures for handling specific HG3 organisms. If universal preventative measures are effectively used, they mitigate against inaccurate or incomplete data used in risk assessment. Forensic practices related to performing autopsies have been largely affected by the COVID-19 pandemic due to the highly contagious nature of the virus. Autopsy is essential in order to determine the cause of death in decedents who test positive for SARS-CoV-2 and to discriminate between those who died with COVID-19 and who died from COVID-19.

It is known that the virus is detectable in air for up to three hours, and it is also detectable for up to four hours on metal, up to 24 hours on cardboard, and up to three days on plastic and stainless steel [4]. Many items used in a typical morgue potentially contain viral particles that may have been shed from a body to surrounding instruments and equipment. For example, body bags that are used to transport decedents are made of thick plastic with a full-length zipper. Autopsy tables are typically made of stainless steel, and many of the instruments used in the morgue are made of plastic and steel. Without proper decontamination after each autopsy, the morgue has the potential to be teeming with many infectious COVID-19 particles.
2020, 1 May 2020, and 1 June 2020. The color increases in intensity as the number of cases increases in each country. Data were sourced from the interactive web-based dashboard hosted by the Center for Systems Science and Engineering (CSSE) at Johns Hopkins University, Baltimore, MD, USA [1]

Postmortem examinations provide valuable information about SARS-CoV-2 pathology and physiology, bringing about useful clinical and epidemiological managements that are anticipated to be effective in guiding therapy and orienting patient care [5]. Equally important, postmortem samples may solve unanswered questions, for instance the effects of the infection on the lungs and the involvement of other organs [6-8]. Here we will review our current knowledge of autopsies in the era of COVID-19 and consider the underlying medicolegal investigations to explain the diverse symptomatology, specifically focusing on differences between the United States and Italy.

\section{Overview of medical examiner/coroner systems}

Globally, the role of the medical examiner in most countries today has evolved in some form from the vestiges of the medieval English coroner system and the European continental system under Roman law, which investigated the cause of death in unusual circumstances [9]. Interestingly, the intersection of medical and legal jurisdiction in the adequate fulfillment of duties associated with the work of a medical examiner has long been a cause of public concern. For example, even today in some countries, including some states and counties in the United States (U.S.), laws pertaining to the training and readiness of individuals for entry into the medical examiner position are not well defined. Public concern regarding possible inadequate medical training of medical examiners drove the evolution of this field in the United States. For instance, at the turn of the 
nineteenth century, public opinion facilitated the advancement of technical and medico-jurisdictional preparation for medical examiners. This movement culminated in the United States in the creation of the 1954 Model Post-Mortem Examinations Act (the Act) $[10,11]$. It was meant to provide a means whereby there was assurance of better competence in determining causes of death in cases of criminal liability. The Act was created but it was never enacted into state law or administrative code. It did, however, stimulate the change of approximately half of the coroner positions to medical examiners.

The Act not only defined the modern role of medical examiners, but it also served to contextualize that role in the setting of the modern theory and practice of public health and public health law. For example, the preface to the Act states that "the purpose of the Model Post-Mortem Examinations Act is to provide a means whereby greater competence can be assured in determining causes of death where criminal liability may be involved. Experience has shown that many elected coroners are not well trained in the field of pathology, and the Act would set up in each state an Office headed by a trained pathologist, this Office to have jurisdiction over post-mortem examinations for criminal purposes. The Office would, in general, supersede the authority of Coroner's Offices in this field" [12]. This definition laid the groundwork for distinguishing, at least in the United States, the medical examiners' roles from that of the coroners'. However, even today, a great amount of overlap exists between coroners and medical examiners and due to the federalist-state system, the states are free to determine and independently develop certain aspects of their death investigation systems.

\section{U.S. medical examiner/coroner system}

In describing the death investigation systems in place today, the U.S. Centers for Disease Control and Prevention (CDC) mentions that states may have either medical examiners or coroners' offices or even a combination of both systems, with 16 states and Washington DC having a centralized medical examiner system, 6 states a county or district-based medical examiner system, 14 states a combination of medical examiners and coroners that is administered at a county level, 14 other states with a county-, district-, or parish-based coroner system, and 25 states with an official State Medical Examiner [13]. This list serves to illustrate a very important aspect of the administration and working of the death investigation system in the U.S., namely that of an amalgamation of a centralized and decentralized system, where some states administer death investigation through a State Office, while others have codified this system at the county, district, or parish level. For example, in Maryland and in Oklahoma, there are statewide agencies $[14,15]$, while in Virginia's medical examiner system, there are four district offices [16]. The Oklahoma Office of the Chief Medical Examiner (OCME) is a statewide medical examiner death investigation system. This is significant to public health and from an epidemiological point of view, due to the variation in reporting and data collection systems regarding death cases, is further compounded by the differences in state laws that govern postmortem death investigations. For example, although there are differences in state laws that determine which deaths may be investigated by the medical examiner or coroner's office, the Medical Examiner's and Coroner's Handbook on Death Registration and Fetal Death Reporting published by the National Center for Health Statistics (NCHS) includes directions for investigation of deaths from disease when "the death occurred suddenly and unexpectantly, the decedent was not being treated by a physician, or the death was unattended," helping link the work of the death investigation system to aspects of the public health system [17]. In 2006, the National Association of Medical Examiners (NAME) enacted Forensic Autopsy Performance Standards into the Accreditation Program [18]. These standards established consensus on definitions and the standardization of techniques such as histology, radiology, toxicology, and written reports.

\section{Italian medical examiner/coroner system}

Dissimilar to the U.S. system, in Italy there is no official death investigation agency such as a coroner or medical examiner system that investigates and certifies causes of death. The first Italian legislation about death investigation was issued in 1910, with the "Circolare Fani" [19]. This Ministerial Circular describes in detail the minimum standards for a forensic autopsy. Before that, there were no standardized procedures or rules for forensic autopsies in place. The Circular was written thanks to the work of Prof. Lombroso who, in 1898, inaugurated the first national meeting of Legal Medicine concerning cadaveric examination. The law mandated that two qualified doctors are needed for each autopsy and this practice is still implemented in current criminal casework. No further laws governing the matter were provided after the "Circolare Fani”. Since 2011, a new death certificate, which conforms to European rules dealing with statistical recording (Rule EU $1338 / 08,16.12 .2008$ ) and was designed by the Italian Institute of Statistics (ISTAT) based on previous Italian rules of law, (Royal Law 1265/34 and Law 285/90) has been in use. Prior to 2011, each Italian death certificate consisted of two categories (natural deaths and violent deaths). Currently, for all natural deaths, disease, injury, and intoxication conditions related to the immediate, intermediate and underlying causes of deaths are synopsized along with corresponding postmortem intervals (PMIs). Non-natural deaths (fall, hanging, gunshot, and intoxication) are documented to clarify the manner of death.

In Italy, forensic autopsies are performed under one of two different statutes: 1) judicial autopsies (ordered for forensic purposes) and 2) nonjudicial autopsies (ordered for sanitary reasons). These kinds of autopsies may also serve to answer epidemiological questions, as may be found in cases 
of infectious diseases, environmental problems, etc. [20]. Nonjudicial autopsies which are also known as "riscontro diagnostic," which is Italian for "diagnostic validation," are regulated by the National Health Service and are requested when the cause of death is unknown or when confirmatory diagnostic investigations are needed. In the U.S., the manner of death is classified as accident, homicide, natural, suicide, or undetermined. In contrast to U.S. death certificates, Italian death certificates do not offer an undetermined manner of death.

It is a legal requirement that, when suspicion of a crime arises during a nonjudicial autopsy, the doctor must stop their activity and inform the Judicial Authority [21]. Judicial autopsies are requested by the Prosecutor or by the Court, if it appears that one's death is related to a crime. This is to enable evidence to be collected. The decision whether or not a judicial autopsy has to be performed is left to the discretion of the Prosecutor, based on preliminary information collected by the police and/or by a medical doctor. Indeed, in every case of unexpected, sudden, unexplained or, above all, violent death, as well as in potential medical malpractice cases, the physician who is asked to fill the death certificates must inform the Judicial Authority [22]. Autopsies, in most cases, are carried out by medical doctors specialized in Legal Medicine employed at University or Public Hospitals, or by other qualified physicians. The Prosecutor usually refers to a Legal Medicine Department of a University or Hospital. According to Italian law, any qualified, registered doctors may be called upon to perform a forensic autopsy, even without any proven specialized training or technical experience in the field [23].

The forensic investigation of a medical malpractice case should be performed, in Italy as an overt deontological due, by a team composed of a trained forensic pathologist and a clinician specialized in the involved branch [24]. The Italian criminal justice system is a sort of semi-adversarial system. Not only does the Prosecutor charge his consultant with performing the autopsy and all the necessary verifications, but also the person under investigation and the victim's next of kin (the injured party) can appoint a forensic pathologist as a consultant to stand in at the autopsy and discuss the case with the Prosecutor's consultant [25]. Despite the European recommendations [20], and unlike in the United States, in Italy forensic autopsies are not mandatory, even when the cause and/or manner of death are unclear, or when the death may be connected to a crime. Law enforcement officers sometimes decide if an external examination is enough for the death investigation or if a forensic autopsy has to be performed [25]. Due to costs, a problematic declining autopsy rate is occurring in Italy, as well as in other countries [26]. Despite rising costs, autopsy remains the only way to determine with certainty the cause, manner, and time of death. Another problem is that, often, too much time lapses before a judicial autopsy is done, due to the time-consuming obligation to serve notice on every party involved.

\section{The role of the forensic pathologist in infectious disease surveillance}

The death investigation system serves as a significant conduit for epidemiological data collection and as an important sentinel system in the event of mass pandemics of fatal diseases as in the case of the COVID-19. Determination of the cause of death of mass causalities of disease outbreaks in localized areas of the world and the spread of this information globally are important early warning systems that regulate public health and the public health response including state allocation of resources and policy development.

\section{Infectious disease surveillance in the United States}

Further evidence of the linkage and interdependency of the public health and death investigation systems emanates from an examination of the death reporting and surveillance systems in the United States today. Such systems include "vital statistics," "notifiable disease reporting," "sentinel surveillance," "surveys," "registries," and "administrative data collection systems" [27]. An important example of the impact of the death investigation systems on public health and epidemiology is the vital statistics reporting and database systems. In the U.S., the National Center for Health Statistics (NCHS) publishes vital statistics data and the National Death Index from data collected from all 50 states. This reporting system includes the vital statistics rapid release system with quarterly mortality, natality, and infant mortality provisional estimates which serve as sentinel systems for early warnings regarding disease outbreaks [28]. In fact, the National Vital Statistics System developed an official COVID-19 death data and reporting guidance with daily, weekly, and state-wide updates on coronavirus-related deaths [29].

In 2007, Nolte et al. created a medical examiner/coroner (ME/C) model surveillance system, which they called Med-X designed to "recognize fatal infections of public health importance and deaths due to bioterrorism" using prospective evaluation of death data from New Mexico medical examiner and coroner jurisdictions between 2000 and 2002 focusing on infectious diseases-related mortality [30]. Since then, multiple efforts have concentrated on the expansion of this program as it is based on accepted standards for autopsy performance, diagnostic testing, and public health reporting. One such instance is the effort to assess the capacity of national ME/C offices to carry out infectious disease surveillance via the administration of an internet-based questionnaire through the National Association of Medical Examiners which determined that of those ME/C offices that responded " $97 \%$ indicated an interest in a medical examiner-based surveillance system for infectious diseases; $13 \%$ currently identify and report cases through the Med-X system" [31]. 
Historically, ME/C surveillance data has provided important information regarding the spread of infections in the events of unusual and sudden mass deaths. These data have traditionally served as significant sources for disease surveillance in outbreaks such as the 2009 H1N1 pandemic in Minnesota, New Mexico, and Oregon, where "surveillance using unexplained death and medical examiner data allowed for detection of $34(18 \%)$ pandemic (H1N1) 2009-associated deaths that were not detected by hospital-based surveillance [32]".

The central role of the ME/C office in investigative infectious disease surveillance and public health reporting is perhaps best exemplified by the events associated with the unfolding of the 1994 Hantavirus Pulmonary Syndrome (HPS) as reported in the August 5th, 1994, Morbidity and Mortality Weekly Report of the CDC. It was reported that a 22-year old Rhode Island man died of acute respiratory distress syndrome approximately five hours after hospitalization which resulted in the engagement of ME/C offices. Postmortem tissue antigen and blood antibodies analysis pointed to hantavirus infection by Muerto Canyon Virus (MCV). Subsequent tracking data and further analysis demonstrated that by July 1994, 83 HPS cases had been identified in the U.S. [32].

Similarly, medical examiners in the United States played a central role in discovering and identifying the West Nile Virus (WNV) infections in New York in 1999. Sampson et al. reported the discovery of deaths associated with WNV infections by postmortem examination of tissue samples through the use of immunohistochemistry (IHC) and polymerase chain reaction (PCR) technologies in New York City in the late summer of 1999. It was reported that the fatalities occurred in persons with a mean age of 81.5 years, with symptoms upon first reporting which included fever and profound muscle weakness. ME/C based autopsy disclosed encephalitis in two instances of deaths and revealed meningoencephalitis in the remaining two cases [33]. WNV was first discovered globally in 1937 in Africa, and following this 1999 discovery in New York City, it has spread across the United States.

\section{Infectious disease surveillance in Italy}

In Italy, infectious disease surveillance is based on the mandatory reporting system [34] that involves the compulsory reporting by physicians to the National Health Service in cases of diagnoses of an established number of diseases. Recently introduced European regulations, establish a new definition of cases in which it is necessary to report transmissible disease to the EU surveillance network and the obligation to collect, analyze, validate, and submit data [35]. The Department of Infectious Diseases prevents diseases due to infectious agents (viruses, bacteria, fungi, and parasites) through the study of human pathogens, host immune responses, and treatment of infections. This department is involved in all the activities related to diagnosis, surveillance, control, epidemiology, and advice in infectious diseases [36]. For example, in Italy, several national and regional surveillance systems are used to monitor seasonal influenza cases. The national surveillance network, InfluNET, used during the H1N1 pandemic, monitored data from the "sentinel physicians" system, which consisted of a national network of approximately 1000 primary care physicians and pediatricians in the 21 regions and autonomous provinces [37]. Incidence rates were therefore not based on consultations but on the served population of each reporting physician each week. Another example regards $\mathrm{MNV}$, that, in Italy, is managed through an annually revised plan aiming to reduce the risk of transmission to humans by detecting viral circulation early and triggering both vectorcontrol and substances of human origin ( $\mathrm{SoHO}$ ) safety measures [38]. The plan, coordinated by the Italian Ministry of Health, defines data flow processes to facilitate a rapid response among relevant stakeholders. Regarding the infection by hantavirus, Italy participates in the European surveillance system for this disease, reporting its rare cases [39].

\section{The impact of the COVID-19 emergency on medicolegal practices}

The outbreak of COVID-19 created a global health crisis that has had a deep impact on medicolegal practices in the U.S. and Italy including autopsy recommendations and
Table 1 Impact of the COVID19 emergency in the United States and Italy. Comparison between the United States and Italy of COVID-19-related data and routine forensic pathologist activity

\begin{tabular}{lll}
\hline & United States & Italy \\
\hline Population & $328,200,000$ & $60,360,000$ \\
COVID-19 cases & $1,750,000$ & 232,248 \\
COVID-19 deaths & 104,000 & 33,340 \\
Date of the first discovered case & January 20, 2020 & February 21, 2020 \\
Beginning of the lockdown & March 19-24, 2020 & March 9, 2020 \\
Autopsy recommendations & Only if strictly necessary & Should be avoided \\
Forensic pathologist activity & Decreased & Drastically decreased \\
\hline
\end{tabular}


forensic pathology activity (Table 1). On January 30, 2020, the WHO declared the outbreak a public health emergency of international concern, warning that "all countries should be prepared for containment" [40]. Due to the large and unexpected number of COVID-19 cases, there is a critical need for swabs for COVID-19 RNA testing and personal protective equipment (PPE) such as gloves, goggles, and masks [41-46]. Additionally, the provisional recruitment of new healthcare specialist personnel is required to meet the demand for COVID-19 patient care [47]. During the COVID-19 pandemic, due to the high number of deaths, governments have had limited choices in handling the large volume of bodies. In countries such as the U. S. and Italy, temporary mortuaries big enough to accommodate thousands of bodies have been assembled. Autopsies have been generally discouraged due to the risk of further spreading the disease through the handling and dissection of bodies [48]. There is still, however, a paucity of data regarding the persistence of SARS-CoV-2 in bodies, as well as concerning the reliability of swabbing methods in human remains. To the best of our knowledge, to date, there has been no scientific confirmation of disease transmission from a body to an medical examiner after an autopsy of a COVID-19 case, even if, in April, a published article [49] was misinterpreted by the media [50,51]. As the coronavirus pandemic has unfolded, forensic pathologists have played (and are still playing) an important role because they are called on to investigate and determine the causes of deaths that are unexpected or unnatural, including deaths that occur at home.

On January 3, 2020 the U.S. declared the COVID19 outbreak a public health emergency [52]. Although by that date, there were only seven known cases in the U.S., the United States Department of Health and Human Service and CDC reported there was a likelihood of further cases appearing in the country. On April 5, 2020 the Council for State and Territorial Epidemiologists issued an interim novel coronavirus position statement [53] that provided a COVID-19 case definition and made COVID19 a nationally notifiable disease. If family or friends say the person had symptoms consistent with COVID-19, the coroner's office could decide to do a nasal swab to test for the virus (this happens, for example, in Richland County, S.C. and in the San Francisco area). Nasal swabbing was typically performed on decedents who manifested one or more of the following clinical symptoms: exposure to an infected person, elevated temperature, cough of respiratory discharge, loss of taste and smell, diarrhea, and/or chest pain. The following comorbidity information was also collected: diabetes, hypertension, obesity, dementia, etc. Medical personnel are required to immediately report to their local or state's health department in the event of the positive identification of a case with known or suspected COVID-19. More recently, the equipment gradually became more widely available and is now easier for pathologists to perform postmortem tests. Currently, months after the emergence of COVID-19 in the United States, the access to test kits and testing materials such as nasal swabs have become readily available.

According to CDC recommendation [54], specific contact and airborne precautions should be followed during autopsy for someone who has known or suspected COVID-19 infection. Many of the procedures are consistent with existing guidelines for safe work practices in the autopsy setting. In particular, in cases of SARSCoV-2 positivity, autopsies must be performed in rooms especially equipped against airborne infections, with negative pressure, and 6-12 air changes per hour.

Italy was the first European country to have a serious outbreak of COVID-19. The infection was confirmed to have spread to Italy on January 31, 2020, when two Chinese tourists tested positive for SARS-CoV-2 in Rome [55]. A circular issued by the Italian Ministry of Health on March 9, 2020 provided an update and replacement of the previous ones and outlined the definition of a suspected, probable, and confirmed case of COVID-19 [56]. Deaths in hospitals are generally assessed as natural, though some EU member states have issued their own statements regarding COVID-19. In Italy, death in the context of COVID-19 should be indicated on the death certificate [57]. It is necessary to indicate if the infection is only suspected or if there is a confirmed antemortem diagnosis of coronavirus. It is also recommended that it is indicated on the death certificate if the virus is directly or indirectly connected to the death, or if the death happened from other causes (for example, from a trauma) in a patient with a confirmed positive COVID-19 swab.

In accordance with the directions issued by the Ministry of Health in its circular published in February 2020 [58], all certifications recording COVID-19 as the cause of death should be accompanied by an opinion of the Istituto Superiore di Sanità (ISS). A working group has therefore been created to study the cause of death of patients who tested positive for SARS-CoV-2 [59]. In most cases, a postmortem examination is not required unless other circumstances make it necessary. Every single case is evaluated based on medical records and the ISTAT death files, recording the patients' causes of death. Data are collected on a web platform (http:// covid-19.iss.it), which is also used for the national epidemiological and virological surveillance of COVID19 cases in Italy (coordinated by the ISS and established by the Ministry of Health [60]). Furthermore, COVID-19 patients have characteristic chest radiographs that assist in interpretation when external examinations are the only analyses performed. 
On April 1, 2020, the Italian Ministry of Health [61] published an official document on autopsies during the SARS$\mathrm{CoV}-2$ epidemic. In conformity with most of the International recommendations, this circular stated that: i) for the entire period of the emergency phase, autopsies or postmortem diagnostic studies should be avoided in cases of COVID19; ii) the Judicial Authority will evaluate the possibility of limiting the assessment to the external inspection of the body, in all cases where an autopsy is not strictly necessary for forensic reasons; iii) the Public Health Departments of each Region will give the criteria to limit the execution of autopsy in case it is necessary to find out the cause of death. It is not allowed to perform autopsies only for scientific purposes; and iv) autopsies can only be carried out in rooms with adequate safety conditions. Standard autopsy protection, together with specific personal protection equipment, should be used (i.e. double surgical gloves interposed with a layer of cutproof gloves, impermeable long-sleeve gown/apron, goggles or face shield, shoe covers, and surgical cap). Respiratory protection consists of a disposable N-95 or higher respirator. All procedures that may produce aerosol should be avoided. In Italy, there are very few autopsy rooms equipped with the recommended safety standards and it is not possible to perform COVID-19 autopsies in the vast majority of Legal Medicine Departments.

As a matter of fact, in less than two months, medicolegal autopsies have drastically decreased. For example, in two of the most important Institutes of Legal Medicine in Lombardy, in March and in April, the decrease in the number of autopsies being undertaken was approximately $70 \%[47,62]$ compared to the same period in previous years. As the contagion progressed in Italy, stricter rules for the management of the deceased were established [61]. Bodies were not stripped and coated. The transfer of open caskets was prohibited and coffins are sealed immediately. Funeral ceremonies have also been banned, in order to avoid mass gatherings.

Despite these difficulties, North Italy has conducted one of the largest studies regarding the histological analysis of lung tissues of 38 cases who died from COVID-19 and this study was recently submitted for publication. A minimally invasive protocol was adopted. The main relevant finding regards the presence of thrombi in small arterial vessels. This important observation fits into the clinical context of coagulopathy which predominates in these patients and which has become one of the main targets of therapy [6].

\section{Conclusion}

In conclusion, in Italy and in the U.S. the current government regulations, issued in order to limit the spread of the SARSCoV-2, have been established to ensure the safety of medicolegal personnel. However, the regulations have, in some cases, precluded the possibility of obtaining precious data about the pathophysiology of the infection. A strong effort by the authorities in the U.S. and Italy has been made in order to facilitate the execution of postmortem examinations, as the data derived from such activities are very likely to be of paramount importance in improving patient management and prevention of the disease. As stated throughout this review, there are marked differences between autopsy procedures in the U.S. and Italy. For example, in both countries, autopsies are performed in "safe" autopsy rooms with all the required personal protective measures; however, airborne infection isolated rooms are more difficult to find in all Italian Legal Medicine Centers. The death investigation systems in both countries are successful in that they have provided accurate data for infectious disease surveillance across a variety of public platforms. On an ongoing basis, the National Notifiable Diseases Surveillance System (NNDSS) in the U.S. helps the CDC monitor reports of infectious and noninfectious diseases which include a list of about 120 diseases, while the Sistema Nazionale di Sorveglianza Della Mortalità Giornaliera (SiSMG) helps the Ministry of Health in Italy.

Autopsies play a clinical role in criminal cases, but should be more appropriately restricted to research studies, where the collection of cadaver samples may provide new insights into organ damage caused by SARS-CoV-2. One of the obstacles for medicolegal investigations related to conducting autopsies during the COVID-19 pandemic is the tremendous number of cases that must be processed. Furthermore, medical examiners must definitively determine the cause of death in COVID-19-positive cases to discriminate between those who died with COVID-19 along with other disease processes from those who actually died from COVID-19 pathogenesis. The manner of death, sometimes referred to as circumstances of death, is also reported on death certificates in COVID-19 cases. Another obstacle is that natural deaths are generally due solely or almost entirely to the aging process or due to disease [63]. However, in the cases of deaths caused by COVID-19 infection, the manner of death is almost always reported as a natural death. In conclusion, recommendations related to SARS-CoV-2 medicolegal investigations in the U.S. and Italy require stronger regulations by government authorities to facilitate accurate completion of postmortem examinations that include upper and lower respiratory tract swabs from each lung, the use of appropriate PPE, and proper infection control practices.

\section{Key points}

1. Medicolegal activities involving autopsies have been greatly affected by the COVID-19 pandemic.

2. Forensic pathologists play a pivotal role in informing infectious disease surveillance. 
3. During the COVID-19 pandemic, there is a risk of spreading the disease through the handling and dissection of bodies.

4. The collection of cadaver samples may provide new insights into organ damage caused by COVID-19.

Acknowledgement This review paper was supported by National Science Foundation \#2011764 and National Institute of Justice 2017-MUMU-4042 grants.

\section{References}

1. Dong E, Du H, Gardner L. An interactive web-based dashboard to track COVID-19 in real time. Lancet Infect Dis. 2020;20:533-4.

2. Covid-19 situation report update. http://www.salute.gov.it/portale/news/ p3_2_1_1_1.jsp?lingua $=$ italiano\&menu=notizie\&p=dalministero\& id=4832. Accessed 29 May 2020.

3. Italian Ministry of Health Centers for Disease Control and Prevention - Coronavirus Disease 2019 (COVID-19) Cases in the U.S. https://www.cdc.gov/coronavirus/2019-ncov/cases-updates/ cases-in-us.html. Accessed 29 May 2020.

4. van Doremalen N, Bushmaker T, Morris DH, Holbrook MG, Gamble A, Williamson BN, et al. Aerosol and surface stability of SARS-CoV-2 as compared with SARS-CoV-1. N Eng J Med. 2020;382:1564-7.

5. College of American Pathologists. COVID-19 Autopsy Guideline Statement from the CAP Autopsy Committee. https://documents. cap.org/documents/COVID-Autopsy-Statement-05may2020.pdf. Accessed 15 May 2020.

6. Carsana L, Sonzogni A, Nasr A, Rossi R, Pellegrinelli A, Zerbi P, et al. Pulmonary post-mortem findings in a large series of COVID19 cases from Northern Italy. medRxiv (preprint). 2020. https:// doi.org/10.1101/2020.04.19.20054262

7. Wichmann D, Sperhake JP, Lütgehetmann M, Steurer S, Edler C, Heinemann A, et al. Autopsy findings and venous thromboembolism in patients with COVID-19: a prospective cohort study. Ann Intern Med. 2020. https://doi.org/10.7326/M20-2003.

8. Chong PY, Chui P, Ling AE, et al. Analysis of deaths during the severe acute respiratory syndrome (SARS) epidemic in Singapore: challenges in determining a SARS diagnosis. Arch Pathol Lab Med. 2004;128:195-204.

9. Houston RA. The Coroners of Northern Britain C. 1300-1700. New York: Palgrave Macmillan; 2014.

10. Jentzen JM. Death investigation in America: coroners, medical examiners, and the pursuit of medical certainty. Harvard: Harvard University Press; 2010.

11. Hanzlick RL. A synoptic review of the 1954 "model postmortem examinations act." Ac Forensic Pathol. 2014;4:451-4.

12. Centers for Disease Control and Prevention. Division of Public Health Surveillance and Informatics. Model Post-Mortem Examinations Act. Drafted by the National Conference Of Commissioners On Uniform State Laws https://name.memberclicks. net/assets/docs/b12bad44-5ae2-4e99-b513-39190b12a456.pdf Accessed 10 May 2020.

13. Centers for Disease Control and Prevention. Public Health Professionals Gateway. Death Investigation Systems. https://www. cdc.gov/phlp/publications/coroner/death.html. Accessed 10 May 2020.

14. Maryland Department of Health, Office of the Chief Medical Examiner-OCME. https://health.maryland.gov/ocme/Pages/ Home.aspx. Accessed 15 May 2020.
15. Barton LM, Duval EJ, Stroberg E, Ghosh S, Mukhopadhyay S. COVID-19 Autopsies, Oklahoma, USA. Am J Clin Pathol. 2020;153:725-33.

16. Virginia Department of Health. https://www.vdh.virginia.gov/ medical-examiner/district-offices-contact-us/. Accessed 15 May 2020.

17. Hanzlick R. Medical examiners, coroners, and public health: A review and update. Arch Pathol Lab Med. 2006;130:1274-82.

18. Clark SC, Peterson GF. History of the development of forensic autopsy performance standards. Am J Forensic Med Pathol. 2006;27:226-55.

19. Circolare Fani. Italian Ministerial Circular n. 1665 of 30/6/1910 and Ministerial Circular n. 1667 of 24/7/1910. https://www. funerali.org/wp-content/uploads/File/Circolari/cg91006300. htm. Accessed 15 May 2020.

20. Italian Regulation on the Mortuary Police. Art. 5 (D.P.R. 285/1990). http://presidenza.governo.it/USRI/ufficio_studi/ normativa/D.P.R.\%2010\%20settembre\%201990,\%20n.\%20285. pdf. Accessed 15 May 2020.

21. Italian Code of Criminal Procedure. Art. 365. https://lexscripta. it/codici/codice-procedura-penale/articolo-365. Accessed 15 May 2020.

22. di Vella G, Campobasso CP. Death investigation and certification in Italy. Acad Forensic Pathol. 2015;5:454-61.

23. Italian Regulation on the Mortuary Police. Art. 44 (D.P.R. 285/1990). http://presidenza.governo.it/USRI/ufficio_studi/ normativa/D.P.R.\%2010\%20settembre\%201990,\%20n.\%20285. pdf. Accessed 15 May 2020.

24. Council of Europe, Recommendation No. R (99) 3. of the Committee of Ministers to Member States on the harmonisation of medico-legal autopsy rules, 1999. https://www.coe.int/t/dg3/ healthbioethic/texts_and_documents/RecR(99)3.pdf. Accessed 15 May 2020.

25. Castiglione A, Lomi A. Forensic Autopsies in Italy. J Forensic Sci. 1993;38:622-7.

26. Turnbull A, Osborn M, Nicholas N. Hospital autopsy: Endangered or extinct? J Clin Pathol. 2015;68:601-4.

27. Hanzlick R, Parrish RG. The role of medical examiners and coroners in public health surveillance and epidemiologic research. Annu Rev Public Health. 1996;17:383-409.

28. Centers for Disease Control and Prevention. National Center for Health Statistics - Vital Statistics Rapid Release. https://www. cdc.gov/nchs/nvss/vsrr.htm. Accessed 10 May 2020.

29. Centers for Disease Control and Prevention. National Center for Health Statistics - COVID-19 Death Data and Resources. https:// www.cdc.gov/nchs/nvss/covid-19.htm. Accessed 10 May 10 2020.

30. Nolte K, Lathrop S, Nashelsky M, Nine J, Gallaher M, Umland E, et al. "Med-X": a medical examiner surveillance model for bioterrorism and infectious disease mortality. Human Pathol. 2007;38:718-25.

31. Blau DM, Clark SC, Nolte KB. Infectious disease surveillance by medical examiners and coroners. Emerg Infect Dis. 2013;19:821-2.

32. Lees $\mathrm{CH}$, Avery $\mathrm{C}$, Asherin R, et al. Pandemic (H1N1) 2009-associated deaths detected by unexplained death and medical examiner surveillance. Emerg Infect Dis. 2011;17:1479-83.

33. Sampson BA, Ambrosi C, Charlot A, Reiber K, Veress JF, Armbrustmacher V. The pathology of human West Nile Virus infection. Hum Pathol. 2000;31:527-31.

34. Italian Ministerial Decree of 15 December 1990 - Infectious and Transmissible Diseases Information System. (published in the Official Gazette of the Italian Government on 8 January 1991, no. 6). http://www.salute.gov.it/imgs/C_17_normativa_1357_allegato. pdf. Accessed 10 May 2020. 
35. Italian Government, Ministry of Health. The current responses of the National Health Service - The prevention of infectious diseases. http://www.salute.gov.it/rssp/paginaParagrafoRssp.jsp?sezione= risposte $\&$ capitolo $=$ interventi $\&$ lingua $=$ english $\& i d=2814$. Accessed 10 May 2020.

36. European Centre for Disease Prevention and Control - Italian National Institute of Health - ISS. https://www.ecdc.europa.eu/ en/instituto-superiore-di-sanita-epiet. Accessed 12 May 2020.

37. Ajelli M, Merler S, Pugliese A, Rizzo C. Model predictions and evaluation of possible control strategies for the $2009 \mathrm{~A} / \mathrm{H} 1 \mathrm{~N} 1 \mathrm{v}$ influenza pandemic in Italy. Epidemiol Infect. 2011;139:68-79.

38. Riccardo F, Monaco F, Bella A, et al. An early start of West Nile virus seasonal transmission: the added value of One Heath surveillance in detecting early circulation and triggering timely response in Italy, June to July 2018. Euro Surveill. 2018;23:1800427.

39. European Centre for Disease Prevention and Control. Hantavirus infection - Annual Epidemiological Report for 2014. https://www. ecdc.europa.eu/en/publications-data/hantavirus-infection-annualepidemiological-report-2014. Accessed 8 May 2020.

40. Boseley S. WHO declares coronavirus a global health emergency. The Guardian. 2020. https://www.theguardian.com/world/2020/ jan/30/who-declares-coronavirus-a-global-health-emergency. Accessed 30 March 2020.

41. Center for Disease Control and Prevention: National Vital Statistics System. Guidance for certifying deaths due to coronavirus disease 2019 (COVID-19). https://www.cdc.gov/nchs/nvss/covid-19.htm. Accessed 12 April 2020.

42. Occupational Safety and Health Administration (OSHA) COVID19 Control and Prevention. https://www.osha.gov/SLTC/covid-19/ controlprevention.html. Accessed 10 May 2020.

43. Hanley B, Lucas SB, Youd E, Swift B, Osborn M. Autopsy in suspected COVID-19 cases. J Clin Pathol. 2020;73:239-42.

44. World Health Organization (WHO) Infection prevention and control for the safe management of a dead body in the context of COVID-19. 2020. https://apps.who.int/iris/bitstream/handle/ 10665/331538/WHO-COVID-19-IPC_DBMgmt-2020.1-eng.pdf. Accessed 10 May 2020.

45. Fineschi V, Aprile A, Aquila I, et al. Management of the corpse with suspect, probable or confirmed COVID-19 respiratory infection Italian interim recommendations for personnel potentially exposed to material from corpses, including body fluids, in morgue structures and during autopsy practice. Pathologica. 2020;112:64-77.

46. Fais P, Gavelli S, Bolino G, Campobasso CP, Cecchetto G, Cecchi $\mathrm{R}$, -et al. Recommendations for forensic autopsy in suspected SARSCOV-2 infected corpses. Italian Rev Legal Med Law Healthcare Area. (in press).

47. Cattaneo C. Forensic medicine in the time of COVID 19: An editorial from Milano. Italy Forensic Sci Int. 2020;312:110308.

48. Hanley B, Lucas SB, Youd E, et al. Autopsy in suspected COVID19 cases. J Clin Pathol. 2020;73:239-42.

49. Sriwijitalai W, Wiwanitkit V. COVID-19 in forensic medicine unit personnel: Observation from Thailand. J Forensic Leg Med. 2020a;72:101964.

50. Sriwijitalai W, Wiwanitkit V. Corrigendum to "COVID-19 in forensic medicine unit personnel: Observation from Thailand" [ $\mathrm{J}$ Forensic Legal Med 72 May 2020, 101964]. J Forensic Leg Med. 2020b;72:101967.
51. Taylor M. COVID-19 was not spread to medical examiner from body. Forensic: on the scene and in the lab. 24 April 2020. https:// www.forensicmag.com/563597-Authors-Journal-Issue-CorrectionCOVID-19-Was-Not-Spread-to-Medical-Examiner-from-Body/. Accessed 10 May 2020.

52. Registry of the Institute of Legal Medicine, University of Pavia. Internal database.

53. Council of State and Territorial Epidemiologists. CSTE Interim Position Statement: COVID-19 Case Definition and Addition to the NNC List. https://www.cste.org/news/500750/CSTE-InterimPosition-Statement-COVID-19-Case-Definition-and-Addition-tothe-NNC-List.htm. Accessed 10 May 2020.

54. Centers for Disease Control and Prevention (CDC). Collection and submission of postmortem specimens from deceased persons with known or suspected COVID-19, March 2020 (Interim Guidance). 2020. https://www.cdc.gov/coronavirus/2019-ncov/hcp/guidancepostmortem-specimens.html. Accessed 10 May 2020.

55. Coronavirus: First two cases in Italy. Corriere della sera. 2020. https://www.corriere.it/cronache/20_gennaio_30/coronavirusitalia-corona-9d6dc436-4343-11ea-bdc8-faf1f56f19b7.shtml. Accessed 31 January 2020.

56. European Centre for Disease Prevention and Control. - Italian National Institute of Health - ISS. https://www.ecdc.europa.eu/ en/instituto-superiore-di-sanita-epiet. Accessed 20 May 2020.

57. Italian National Institute of Statistics. COVID-19: instructions for completing the death certificate. 2020. https://www.istat.it/it/ files//2020/03/Covid_Indicazioni_scheda_morte.pdf. Accessed 11 May 2020.

58. Circular published by the Ministry of Health on 25 February 2020. http://www.trovanorme.salute.gov.it/norme/renderNormsanPdf? anno $=2020 \&$ codLeg $=73368 \&$ parte $=1 \% 20 \&$ serie $=$ null. Accessed 15 May 2020.

59. Istituto Superiore di Sanità. National surveillance (epidemiological and virological) of COVID-19 cases in Italy - Epidemiology for public health. https://www.epicentro.iss.it/en/coronavirus/sarscov-2-analysis-of-deaths. Accessed 12 May 2020.

60. Ministry of Health. Ministerial circular n. 1997 of 22 January 2020. https://www.lavoripubblici.it/documenti2020/lvpb1/Circolare_ Min_Salute_22_01_2020_1997.pdf. Accessed 12 May 2020.

61. Indicazioni emergenziali connesse ad epidemia COVID-19 riguardanti il settore funebre, cimiteriale e di cremazione. Ministero della Salute-Direzione Generale Della Prevenzione Sanitaria. Ufficio 4 - 0011285-01/04/2020-DGPRE-DGPRE-P. http://www.trovanorme.salute.gov.it/norme/renderNormsanPdf? anno $=2020 \&$ codLeg $=73789 \&$ parte $=1 \% 20 \&$ serie $=$ null . Accessed 11 May 2020.

62. US declares public health emergency from coronavirus. Boston Globe. 2020. https://www.bostonglobe.com/news/nation/ 2020/01/31/declares-public-health-emergency-from-coronavirus/ 9WMXL38AdA08GJworROtII/story.html. Accessed 12 May 2020.

63. National Center for Health Statistics. Medical examiner's and coroner's handbook on death registration and fetal death reporting. https://www.cdc.gov/nchs/data/misc/hb_me.pdf. Accessed 12 May 2020.

Publisher's Note Springer Nature remains neutral with regard to jurisdictional claims in published maps and institutional affiliations. 